\title{
ESTUDO EXPLORATÓRIO - SIMILARIDADES E DIFERENÇAS NA SITUAÇÃO PSICOTERAPÊUTICA: COMPORTAMENTO NÃO-VERBAL DO PSICOTERAPEUTA EM DIFERENTES ABORDAGENS TEÓRICAS ${ }^{\star}$
}

Maria Ester Rodrigues

\begin{abstract}
RESUMO
O presente trabalho teve por objetivo observar e descrever o comportamento não-verbal de três psicoterapeutas de abordagens diferenciadas, a fim de identificar similaridades e diferenças entre os mesmos, tendo como pano de fundo teórico o movimento denominado Integração Terapêutica e a própria bibliografia de Comunicação Não-Verbal. Foram analisadas fitas gravadas de 9 sessões psicoterapêuticas, três sessões de cada terapeuta. As categorias de comportamento selecionadas foram registradas em intervalos de 10 segundos. Todos os terapeutas $^{\star * *}$ apresentaram comportamentos descritos na literatura como típicos de afiliação, empatia e/ou interesse no inter-
\end{abstract}

Pesquisa realizada como requisito parcial para obtenção do título de Especialista no Curso de Pós-Graduação Lato Sensu em Psicologia Clínica - Modalidade Behaviorismo, oferecido pelo Departamento de Psicologia da Universidade Federal do Paraná, orientada pela Profa. Yara K. Ingberman.

UNIOESTE - Departamento de Educação - Rua Universitária, 2069, Jardim Universitário 85814-110, Cascavel - PR - Fone (045) 225-2100 R: 305 Fax: (045) 223-4584 - e-mail: ester@certto.com.br. 
locutor, mostrando-se como pessoas potencialmente reforçadoras. Foram observadas algumas diferenças no comportamento, provavelmente ligadas à abordagem teórica de cada terapeuta, como a presença de toque do paciente apresentado pelo terapeuta reichiano; a maior quantidade de fala e de movimentação generalizada (mãos, braços, cabeça, etc.), apresentada pela terapeuta comportamental e a redução de freqüência desses mesmos comportamentos no caso da terapeuta lacaniana. A maior parte das categorias de comportamento observadas foram apresentadas pelos três terapeutas. As principais diferenças residiram, portanto, na freqüência com que cada categoria foi emitida pelos terapeutas.

A bibliografia em Psicoterapia é pródiga em fornecer descrições e análises do comportamento dos pacientes em geral, dentro das mais variadas abordagens teóricas. O mesmo não ocorre em relação à descrição do comportamento dos psicoterapeutas. A pesquisa em Psicoterapia baseia-se mais em resultados de procedimentos que os terapeutas dizem executar do que em observações empíricas de suas ações concretas. Além dessa inexatidão dos relatos de atividades terapêuticas, as discussões sobre o que acontece em psicoterapia são teóricas e apoiadas em diferentes referenciais e diferentes linguagens, o que torna o debate sobre tais procedimentos especialmente difícil. É possível que existam práticas comuns a uma cultura terapêutica, que surgem da solução de problemas clínicos e que se referem a estratégias clínicas comuns a diferentes orientações. Também é possível que as diferenças teóricas realmente determinem cursos de ação muito diferenciados. De acordo com a literatura, uma das maneiras mais eficientes de detectar a existência ou inexistência de tais práticas é por meio da observação e comparação de comportamentos de psicoterapeutas de diferentes abordagens teóricas em situação terapêutica. 
A existência de dados conflitantes na bibliografia investigada, sobre semelhanças ou diferenças em práticas clínicas de terapeutas com diferentes orientações teóricas, aliada à inexistência de uma linguagem comum a tais abordagens, gerou a opção por escolher comportamentos não-verbais como categoria de observação do comportamento de psicoterapeutas. Essa opção proporciona maior objetividade e concordância na observação e permite a descrição do comportamento do psicoterapeuta sem a necessidade de recorrer a construtos explicativos próprios da abordagem do terapeuta em questão. Embora o comportamento não-verbal seja analisado dentro de um sistema verbal próprio e, portanto, isento de neutralidade, possui a vantagem de não ser um sistema conceptual utilizado por abordagens psicoterapêuticas.

O artigo apresenta uma breve revisão de bibliografia sobre os temas envolvidos na problematização e justificativa apresentadas para a pesquisa, quais sejam, a questão da Integração e Ecletismo terapêuticos. Há, ainda, a revisão de alguns aspectos básicos da Comunicação Não-Verbal que embasarão a discussão dos dados.

\section{INTEGRAÇÃO TERAPÊUTICA}

Para GOLDFRIED (1982), qualquer tentativa de encontrar pontos comuns em estratégias terapêuticas que perpassem diferentes orientações deve estar baseada no que os terapeutas fazem, ao invés de no que eles dizem fazer, por intermédio de uma observação empírica da realidade, isso porque terapeutas podem ser observadores falhos de sua própria atividade.

Althoug one can enumerate what appear to be common therapeutic strategies cutting across different orientations, the generation of these strategies is based on what therapists 'say they do', not what they 'actually do'....... In the final analysis, what is clearly needed is a more direct empiri- 
cal test of what similarities actually exist across different orientations (GOLDFRIED, 1982, p. 586-587) ${ }^{1}$.

HAAGA (1986) e GOLDFRIED (1982) argumentam que a pesquisa de princípios comuns e similaridades entre psicoterapeutas e psicoterapias deve ser feita de modo empírico, baseando-se no que os terapeutas e clientes efetivamente fazem, ao invés de no que os terapeutas pensam sobre isso. Além disso, argumentam que alguns procedimentos técnicos perpassam diferentes orientações, embora sejam descritos com linguagem própria de cada teoria,

A literatura em clínica psicológica relata algumas tentativas de aproximação entre diferentes abordagens, na criação de uma prática clínica que contenha elementos comuns. Tais tentativas estão ligadas a um movimento denominado Integração Terapêutica. Esse tema é bastante controvertido e apresenta, de um lado, defensores dedicados e de outro, críticos severos.

GOLDFRIED (1982) apresentou uma extensiva revisão de bibliografia na área da Integração Terapêutica. O autor mostra que a esperança de encontrar um modo de aproximar e integrar várias abordagens de psicoterapia, data dos anos 30. No entanto, a maior concentração de trabalhos dessa natureza ocorreu após a década de 60. O conceito de ecletismo técnico, foi introduzido na década de 60, afirmando ser possível utilizar técnicas eficazes vindas de diferentes sistemas terapêuticos sem aceitar, necessariamente, as bases teóricas associadas a estes métodos. Nos anos 80, os clínicos apresentaram tendência crescente a olhar em direção a fatores comuns a todas as escolas de pensamento e a incorporar procedimentos vindos de outras orientações terapêuticas.

\footnotetext{
Embora alguém possa enumerar o que aparece de comum em estratégias terapêuticasque perpassam diferentes orientações, a origem dessas estratégias está baseada no que os terapeutas "dizem fazer", não no que 'realmente fazem Numa análise final, o claramente necessário é um teste mais diretamente empírico sobre as similaridades realmente existentes através de diferentes orientações.
} 
O ecletismo em Psicoterapia, ou mesmo termos como integracionismo ou convergência terapêutica, são geralmente percebidos como adesão a uma abordagem não-sistemática e caótica. Para WOOLFOLK (1992), a integração psicoterapêutica é um complexo movimento que tem múltiplas causas. Para ele, integracionismo e ecletismo seriam uma espécie de ecumenismo terapêutico que floresceu no relativismo da corrente Zeitgeist. Esse relativismo tende a promover pluralismo teórico e metodológico. Existem, no entanto, inúmeras barreiras para uma integração teórica entre psicoterapias. GARFIELD (1982) afirma que é o real comportamento dos terapeutas e não suas orientações teóricas que influencia o processo e os resultados da terapia. Os terapeutas podem, no entanto, ser inconscientes de seus comportamentos (não discriminar suficientemente suas próprias ações) e falhar no conhecimento de seus possíveis significados. Rogers, por exemplo, nunca enfatizou reforço verbal como variável na Terapia Centrada no Cliente, mas seu uso foi detectado em mais de um estudo, como os de MURRAY e TRUAX apud GARFIELD (1982).

\begin{abstract}
Although adherents of particular schools of psychotherapy tend to emphasize their particular approach and its distinctly unique aspects, their descriptions of their therapy may not (and frequently do not) correspond to their actual behaviors and interactions in the therapeutic situations (GARFIELD, 1982, p. 616) $)^{2}$.
\end{abstract}

$\mathrm{Na}$ bibliografia da área, encontramos os termos Ecletismo e Integração usados como sinônimos, embora o primeiro se refira mais ao ecletismo técnico, ou seja, o uso de procedimentos potencialmente eficazes provenientes de diferentes abordagens. Integração implicaria alguma forma de junção teórica ou conceitual.

2 Enquanto simpatizantes de determinadas escolas de psicoterapia tendem a enfatizar suas próprias abordagens e seus aspectos únicos distintos, as descrições de suas terapias podem não corresponder (e freqüentemente não correspondem), aos seus comportamentos e interações reais nas situações terapêuticas (GARFIELD, 1982, p. 616).

Interação, Curitiba, v. 1, p. 95-122, jan./dez. 1997 
A Integração Terapêutica esbarra, no entanto, na questão da diferença de linguagens dentro do universo terapêutico. Os proponentes da Integração Terapêutica, GOLDFRIED (1982) e GOLDFRIED e PADAWER (1982), sugeriram o uso de de uma linguagem neutra, ou mesmo o uso da linguagem cognitiva contemporânea, para superar o problema. Para O'DONOHUE e MCKELVIE (1993), essa escolha coloca em risco a alegada neutralidade, além do que seria muito difícil traduzir a linguagem de uma teoria em particular, sem despir essa mesma teoria de suas conotações teóricas e conteúdos epistemológicos e ontológicos peculiares. Existem inúmeras maneiras de correlacionar o observado com possíveis interpretações dentro de infinitos contextos, visões de mundo, pressupostos e conceitos. Essa questão é extensamente analisada na história do Conhecimento, da Ciência e da Filosofia.

Apesar de todas as dificuldades, há uma tentativa crescente entre psicoterapeutas em ignorar as barreiras ideológicas que dividem escolas de psicoterapia e em definir o que elas têm em comum e o que pode ser útil em cada uma delas. KARASU apud BEITMAN et al. (1989) contou mais de 400 diferentes escolas de psicoterapia. As muitas críticas a tal proliferação e tentativas de integração são descritas pelos autores como insultos pueris baseados em rivalidade, antipatias mútuas e descrédito. Essa proliferação de procedimentos terapêuticos tem florescido e se articulado. Uma revista internacional, o Journal of Integrative and Eclectic Psychotherapy (Revista de Psicoterapia Eclética e Integracionista) e muitos artigos voltados ao tema apareceram na década de 80 . Duas organizações interdisciplinares também surgiram: Society for the Exploration of Psychotherapy Integration e o International Academy of Eclectic Psychoterapists (Sociedade para a exploração da Integração Psicoterapêutica e a Academia Internacional de Psicoterapeutas Ecléticos). 
BEITMAN et al. (1989) apontam como exemplo de Integração Terapêutica bem-sucedida os procedimentos teórico-técnicos que promovem a interação entre aspectos como Cognição, Afetos e Comportamentos. O exemplo apontado contém alguns problemas que sustentam as principais críticas ao movimento integracionista: a confusão teórico-epistemológica. A despeito das diferenças entre pressupostos e objetivos de terapias comportamentais e psicodinâmicas, dentro de um referencial de Behaviorismo Radical, podemos afirmar que afetos e cognições são também considerados comportamentos que, embora encobertos, não são de natureza diferente dos demais.

BRANCH (1987) afirma que o terapeuta comportamental é freqüentemente descrito pelos demais ou por si próprio como "eclético" em orientação, no sentido de privilegiar o uso de técnicas que se tenham mostrado efetivas em detrimento do uso de uma abordagem teórica em particular. No entanto, essa vocação eclética não é avaliada positivamente pelo autor que, ao contrário, aponta-a como exemplo de covardia intelectual. Desenvolver e entender uma posição teórica é uma tarefa difícil, mas é justamente o que leva ao desenvolvimento científico e tecnológico. Adotar uma posição teórica permite ao terapeuta, entre outras coisas, saber por que as técnicas utilizadas são efetivas.

POPPER apud O'DONOHUE e MCKELVIE (1993) argumentou persuasivamente que a crítica é essencial ao crescimento da Cência. Neste sentido, a pluralidade de alternativas, antes de ser um sintoma de crise, pode ser um fator potencialmente impulsionador do crescimento científico (teórico e técnico). De fato, o avanço em Ciência não está historicamente ligado a integrações e sim a mudanças e avanços substanciais em métodos, técnicas e teorias, apoiados no que de mais concreto possa haver sobre os experimentos científicos, os dados obtidos.

O movimento eclético-ecumênico-integracionista em psicoterapia pode trazer mais dúvidas do que soluções. A simples combi- 
nação de procedimentos, técnicas e abordagens não nos esclarece sobre quais seriam as variáveis comuns à maior parte das psicoterapias. O mesmo acontece com terapeutas estritamente ligado a uma identidade teórica e competindo por um melhor conjunto de regras. Permanece a dúvida sobre o que realmente fazem, embora seus comportamentos possam ser melhor operacionalizados.

As nossas visões e interpretações da realidade não são independentes do paradigma que escolhemos, porém resta a dúvida sobre as nossas ações. O que fazem efetivamente terapeutas? Existem diferenças entre ações observáveis de psicoterapeutas de abordagens diferenciadas? As diferenças são apenas teóricas? Parece que uma forma apropriada de investigar tais questões é observar empiricamente a realidade, fugindo da interpretação do terapeuta sobre o ocorrido e registrando categorias de comportamento passíveis de observação, análise e concordância.

A seguir, apresentaremos alguns aspectos básicos do comportamento não-verbal, a macrocategoria comportamental utilizada para selecionar as categorias específicas observadas neste trabalho e para auxiliar a interpretação dos dados obtidos.

\section{COMPORTAMENTO NÃO-VERBAL}

Comportamento e Comunicação Não-Verbal são uma parte importante no comportamento social humano. Onde interagem duas ou mais pessoas, boa parcela de contato será realizado através de sinais não-verbais dos quais elas nem sempre estarão conscientes, mas que cumprirão o seu papel. Segundo ARGYLE (1988), as pesquisas nessa área incluem expressão facial, olhar, gestos e outros movimentos corporais, contato corporal, comportamento espacial, roupas e outros aspectos da aparência, vocalizações não-verbais e olfato; podendo cada item citado ser dividido em subitens.

Cada um desse canais funciona de modo diferente. As expressões faciais, por exemplo, seriam panculturais e acionadas 
por "programas afetivos" inatos que, segundo SILVA (1989), comandariam a contração/relaxamento de conjuntos específicos de músculos, sofrendo correções posteriores das regras de exibição culturais. Os gestos e movimentos corporais sofrem grande influência cultural e variação intra e intercultural. Muitos sinais não-verbais podem ser bastante sutis e não sofrer controle voluntário; outros são compartilhados por todos os membros de uma dada cultura, intencionais e com claro significado tanto para o receptor quanto para o emissor (ARGYLE, 1988). A fala também é acompanhada por um intrincado conjunto de sinais não-verbais, como tempo de fala, ênfases, tonalidades, etc. A comunicação não-verbal serve a diferentes funções, como expressar emoções, comunicar atitudes interpessoais, acompanhar e dar suporte à fala (paralinguagem), apresentação pessoal, rituais, etc. (ARGYLE, 1988 e OTTA, 1994). A distinção verbal/não-verbal não corresponde, portanto, à vocal/não-vocal; movimentos e expressões podem ser claramente verbais (emblemas, linguagem de sinais, etc.) e vocalizações podem ter conteúdo não-verbal.

Muitas aplicações práticas advêm da pesquisa em Comunicação Não-Verbal. ARGYLE (1988) cita o treino de habilidades interpessoais/sociais e o treinamento de habilidades para o trabaIho. Psicoterapeutas em geral podem vir a aproveitar tais resultados para incrementar e/ou desenvolver habilidades em seu trabaIho (eminentemente interpessoal), tomando consciência dos sinais não-verbais envolvidos que estejam presentes na situação psicoterapêutica. Existem relatos na literatura, de pesquisa sobre comunicação não-verbal de pacientes, como as de EKMAN (1985), sobre a veracidade de emoções relatadas por meio de análise de microexpressões, microgestos e paralinguagem que o terapeuta pode identificar. O comportamento não-verbal de terapeutas não é analisado com o mesmo empenho. Além de uma espécie de tabu social da comunidade terapêutica, analisado por BERNSTEIN (1984), existiria outro fator que poderia ser a menor consciência 
que os emissores da mensagem não-verbal (no caso o terapeuta) têm sobre o que estão emitindo, em comparação com os receptores. Enquanto receptores estamos geralmente, não totalmente e nem para todas as informações, conscientes das informações recebidas, mas, enquanto emissores, nosso grau de ciência diminui (ARGYLE, 1988). Sendo assim, os terapeutas estariam muito mais sob controle dos sinais e pistas emitidos pelos pacientes, do que pelas suas próprias deixas. Isso pode fazer com que o terapeuta possa produzir reações sem se perceber como agente das mesmas. Ainda para o mesmo autor, os sinais não-verbais são menos sujeitos ao controle consciente e, portanto, mais genuínos, além de serem úteis como segundo canal aditivo à linguagem. Essa menor sujeição do comportamento não-verbal ao controle voluntário torna o estudo de sinais não-verbais especialmente interessante no caso da comparação entre o comportamento de diferentes terapeutas e identificação de possíveis similaridades e/ou diferenças.

EKMAN e FRIESEN apud ASTROM et al. (1993) apontaram a importância do comportamento não-verbal no processo psicoterapêutico. Essa importância do comportamento atribui-se em parte ao seu caráter comunicativo e em parte porque certos comportamentos não-verbais são menos suscetíveis ao controle consciente.

ASTROM et al. (1993) estudaram atitudes não-verbais em situações de encontro inicial, quando paciente e terapeuta se cumprimentavam, por meio de um questionário. O principal resultado foi o de que mais de $50 \%$ dos pacientes responderam que a face era o mais importante canal de comunicação não-verbal. Os resultados também mostraram a existência de uma observação consciente de sinais não-verbais durante o encontro inicial pelos pacientes.

GOMEZ e SALAS (1984) aplicaram análise contextual à comunicação não-verbal em uma situação psicoterapêutica (análise de uma sessão terapêutica). Os pesquisadores utilizaram enfo- 
que estrutural com objetivo de descrever padrões típicos de comportamento e explicar a organização e funcionamento do material verbal e não-verbal na criação do evento interativo, incluindo nas categorias de análise o movimento das mãos, da cabeça, a postura, a orientação e a paralinguagem. Concluíram que há a possibilidade de apontar para três funções do comportamento não-verbal, quais sejam:

a) o feedback não-verbal tem função informativa;

b) reduz a ambigüidade da linguagem falada;

c) regula a interação.

LEPPER et al. (1995) forneceram uma revisão de bibliografia sobre modelos de interação não-verbal na relação médicooaciente, acerca da expectativa de ambos sobre o envolvimento do paciente na interação. A relação médico-paciente abarca algumas peculiaridades que, se não reproduzem a relação psicoterapeuta-paciente, a ela muito se assemelham. Para os autores, a contribuição do médico no envolvimento do paciente inclui comportamentos como dar informações, fazer perguntas, construir uma parceria, engajar-se em ouvir, evitando interromper o paciente. Interrupção da fala do interlocutor é descrito como sinal de dominação por ARGYLE (1988) e HENLEY (1977). A contribuição do paciente inclui fazer perguntas, dar informações detalhadas, expressar opiniões e preocupações, ouvir o médico e, se desejar, participar da tomada de decisão sobre o tratamento. Tais comportamentos podem ser promovidos, modificados ou suprimidos, tanto no caso do médico como do paciente, por informações nãoverbais presentes na voz, toque, olhar, postura e expressão facial de ambos.

O sorriso, por exemplo, é uma expressão facial que apresenta um fator regulador de interações sociais humanas muito importante, demonstrando predisposição para continuar mantendo a interação, comunicando sobre o caráter amistoso da mesma e 
inibindo comportamentos hostis. Assim como outras expressões faciais de emoções (surpresa, medo, nojo, desprezo, raiva), o sorriso tem caráter inato. Segundo OTTA (1994), as expressões faciais têm funções expressivas sobre o que se passa internamente com nossas emoções, sendo o aspecto mais estudado pelos psicólogos e também um aspecto regulativo que se refere ao modo como usamos esses sinais em interações sociais, ou seja, às suas funções e significados sociais, tópico que tem merecido menor atenção nas pesquisas da área.

Em virtude da discordância sobre similaridades entre sistemas teórico-metodológicos e da existência de tantas super-estruturas lingüísticas e conceituais, optamos por escolher algumas categorias não-verbais de análise. Elas permitem a observação do comportamento de terapeutas e a comparação entre o tipo e a freqüência dos comportamentos apresentados, permitindo a consecução do objetivo principal do trabalho, qual seja, a verificação de possíveis diferenças e similaridades entre o comportamento de psicoterapeutas que se auto-identificam como adeptos de uma ou outra corrente teórica diferenciada dos demais. A comparação entre conjuntos de comportamentos de psicoterapeutas que se definem como adeptos de diferentes referenciais pode ser um primeiro passo em direção ao reconhecimento das ações dos terapeutas, enquanto comportamentos observáveis e passíveis de análise.

\section{MÉTODO}

Sujeitos: Participaram deste experimento três psicoterapeutas, autodefinidos como de orientação teórica lacaniana, comportamental e reichiana. Os dois primeiros do sexo feminino e o último, do sexo masculino.

Situação Observacional e Equipamento: Foram gravadas três sessões terapêuticas com cada sujeito, no Laboratório de Psicologia do Centro de Psicologia Aplicada do Departamento de 
Psicologia da Universidade Federal do Paraná. O registro foi feito pela pesquisadora com equipamento de áudio e vídeo, através da sala de espelho unidirecional anexa à sala de atendimento.

TABELA 1 - DURAÇÃO DAS TRÊS CADA TERAPEUTA SESSÕES
\begin{tabular}{lcccc}
\multicolumn{5}{c}{ ANALISADAS PARA CADA TERAPEUTA } \\
\hline Terapeuta & Sessão 1 & Sessão 2 & Sessão 3 & Tempo Atual \\
\hline Lacaniano & $33^{\prime}$ & $32^{\prime}$ & $18^{\prime}$ & $1 \mathrm{~h} 23^{\prime}$ \\
Reichiano & $52^{\prime}$ & $59^{\prime}$ & $48^{\prime}$ & $2 \mathrm{~h} 39^{\prime}$ \\
Comportamental & $60^{\prime}$ & $36^{\prime}$ & $41^{\prime}$ & $2 \mathrm{~h} 17^{\prime}$ \\
\hline
\end{tabular}

Procedimentos: Cada sujeito foi observado em três das sessões realizadas no laboratório, por todo o tempo de duração das sessões. Os comportamentos dos sujeitos foram observados e registrados durante as três sessões, que variaram de 15 a 60 minutos de duração, de acordo com a Tabela 1. Os dados foram coletados por meio do registro de intervalos de tempo, em intervalos de 10 segundos. Neste registro, anotamos na casela (espaço correspondente a 10" na folha de registro) a ocorrência ou não das categorias de comportamento listadas, independente da freqüência de ocorrência (mais de uma apresentação no mesmo intervalo de 10 segundos) e do tempo de exposição (se inferior a 10 segundos); como conseqüência, os comportamentos foram anotados de modo seqüencial, simultâneo e não excludentes entre si. A freqüência de comportamentos listados foi analisada em termos de porcentagem de ocorrência nos intervalos, a partir de tratamento estatístico que permitiu a comparação entre sessões de duração diferenciada. Após o cálculo da freqüência de ocorrência de cada comportamento listado em cada sessão, efetuamos o cálculo da média aritmética entre as três sessões de cada terapeuta e procedemos à análise dos dados. 


\section{RESULTADOS E DISCUSSÃO}

Para a análise das principais semelhanças e diferenças no comportamento não-verbal dos três terapeutas de diferentes abordagens, foram registradas as categorias comportamentais listadas na tabela 2, que mostra também a porcentagem de ocorrência de cada uma destas categorias comportamentais, para cada um dos terapeutas observados.

Em relação às principais semelhanças, podem-se citar os comportamentos indicados pela bibliografia como indicadores de atenção, afiliação ou aproximação, naturalmente ou culturalmente reforçadores, que foram encontrados pelos terapeutas observados. A bibliografia aponta para o fato de a atenção ser um reforço do tipo primário (MILLENSON, 1967).

As principais diferenças encontradas estão mais ligadas à freqüência de ocorrência dos comportamentos registrados para os três terapeutas do que ao tipo de comportamento. Apresentam, portanto, os mesmos tipos de comportamento, porém, em freqüência diferenciada.

Os principais comportamentos encontrados como afiliativos, empáticos e/ou reforçadores, de acordo com a bibliografia da comunicação não-verbal foram: sorriso (fechado e aberto); olhar para o paciente; inclinação de cabeça para a frente; assentimento; sobrancelha levantada; tronco inclinado para a frente e "humhum". Os comportamentos considerados não-afiliativos foram: desvios de olhar; inclinação da cabeça para trás; gesto de negação; sobrancelha franzida; braços cruzados e tronco inclinado para trás. 


\section{TABELA 2 FREQÜÊNCIAS DE OCORRÊNCIA DAS CATEGORIAS COMPORTAMENTAIS ANALISADAS PARA CADA TERAPEUTA}

\begin{tabular}{|c|c|c|c|}
\hline CATEGORIAS DE COMPORTAMENTO & $\begin{array}{c}\text { LACANIANO } \\
\%\end{array}$ & $\begin{array}{c}\text { REICHIANO } \\
\%\end{array}$ & $\begin{array}{c}\text { COMPORT. } \\
\%\end{array}$ \\
\hline Sorriso aberto & 5,18 & 7.21 & 30.01 \\
\hline Sorrico fochado & 13.01 & 4,85 & 5,24 \\
\hline Olhat p/paciente & 98,97 & 93.46 & 81,78 \\
\hline Olhar p/baixo & 3 & 11.82 & 23,98 \\
\hline Olhar p/diroita & 0,61 & 1,68 & 6,93 \\
\hline Olhar p/esquerda & 0 & 0,84 & 0.55 \\
\hline Olnar p/ eima & 0.16 & 5,84 & 27,20 \\
\hline Inclinaçäo de cabeça p/cima & 0,86 & 0,30 & 1.05 \\
\hline Inclinaçăo de cabeça p/baixo & 2.25 & 2,40 & 4,70 \\
\hline Inelinacāo do caboça p/ocquorda & 2.68 & 1.64 & 4.94 \\
\hline Inclinaçăo do caboça p/diroita & 7,47 & 2.73 & 20,45 \\
\hline Inelinaçāo do caboca p/frento & 5.32 & 7.45 & 9.26 \\
\hline Inclinaçāo de cabega p/trás & 2,51 & 2,51 & 13,42 \\
\hline Gesto de assertimento & 21,94 & 47,21 & 59,46 \\
\hline Gesto de negaçక̆o & 3.88 & 7,08 & 10,93 \\
\hline Sobrancolhae orguidas & 7.88 & 18,77 & 20,89 \\
\hline Sobrancolhas franzidas & 1.42 & 0,29 & 0.33 \\
\hline Măos om movimonto com a fala & 2,72 & 15.98 & 31.56 \\
\hline Mäos em gesto ilustrativo da fala & $\circ$ & 0.33 & 1,76 \\
\hline Măos tocam o paciente & 0 & 17,30 & 0 \\
\hline Braços cruzados & 60.97 & 0 & 0.09 \\
\hline Bracos em movimento com fala & 3,25 & 10,96 & 44.35 \\
\hline Braços em gosto ilustrativo da fala & 0,67 & 0.23 & 5,34 \\
\hline Tronco p/frente & 0,47 & 2,33 & 3,43 \\
\hline Tronco $\mathrm{p} /$ trase & 1,29 & 1.17 & 4,41 \\
\hline Pernas cruzadas & 85,50 & 73,32 & 44,56 \\
\hline Pernas lado a lado & 13,77 & 0.11 & 51,58 \\
\hline Hum-Hum & 14,81 & 14,45 & 8,61 \\
\hline Fala & 14,07 & 24,09 & 71,93 \\
\hline Comportamontos năo-afiliativos & 167,58 & 195,73 & 218,68 \\
\hline Comportamentos nâo-afiliativos & 73,84 & 31,23 & 87,84 \\
\hline
\end{tabular}


Na figura 1 observa-se o predomínio dos comportamentos afiliativos em relação aos não-afiliativos. Os primeiros em sentido crescente, na ordem lacaniano, reichiano e comportamental. O terapeuta reichiano apresentou o menor índice de comportamentos não-afillativos.

\section{FIGURA 1 - PORCENTAGEM DE FREQÜÊNCIA TOTAL DE COMPORTAMENTOS CONSIDERADOS AFILIATIVOS E NÃO-AFILIATIVOS PARA CADA TERAPEUTA}

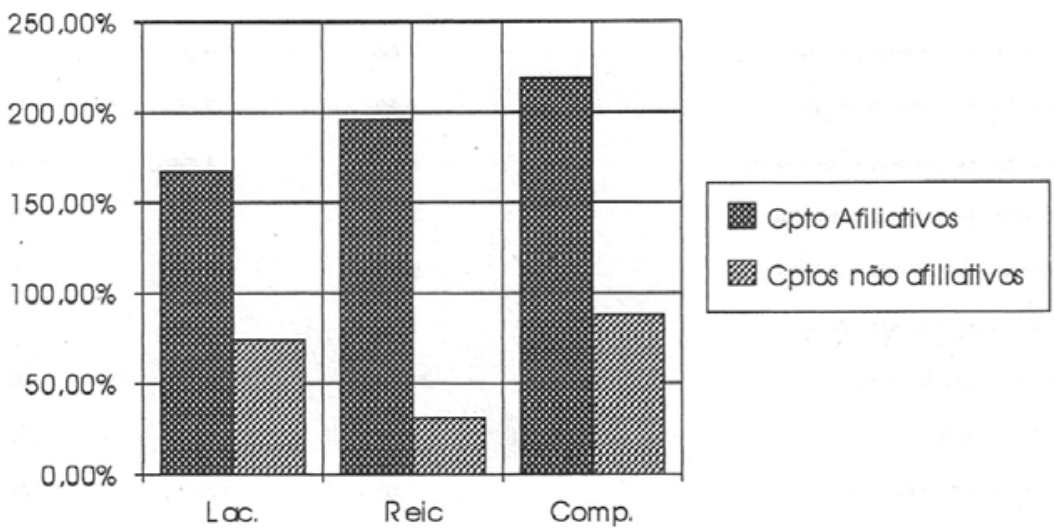

O sorriso dos terapeutas, de acordo com a literatura, pode ser interpretado como: sinal de empatia, reforço inespecífico ou específico. OTTA (1994) e HENLEY (1977) apontam para uma diferença na freqüência de sorriso entre os sexos. O terapeuta reichiano, único do sexo masculino na amostra, apresentou a menor freqüência geral de sorriso entre os três terapeutas da amostra. A terapeuta comportamental apresentou freqüência maior de sorriso aberto (com exposição de dentes) e a lacaniana, o inverso. Estes dados encontram-se na figura 2. 


\section{FIGURA 2 - FREQÜÊNCIA DE APRESENTAÇÃO DE SORRISOS ABERTOS, SORRISOS FECHADOS E SOMATÓRIA DE FREQÜÊNCIA DE AMBOS OS TIPOS DE SORRISOS PARA CADA TERAPEUTA}

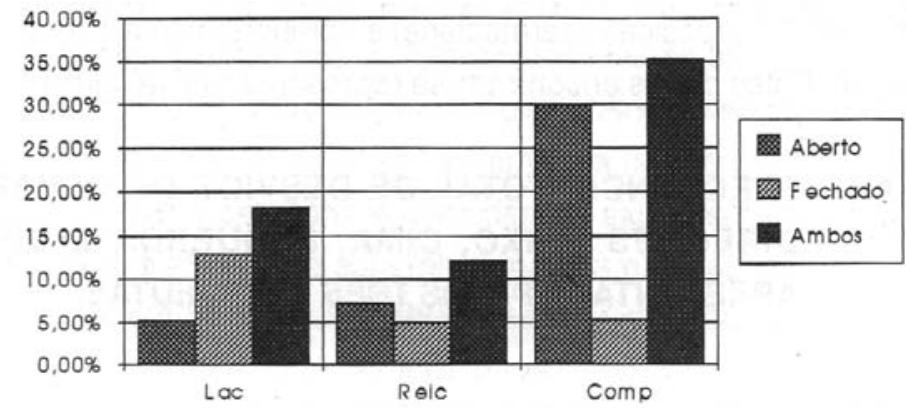

O olhar também é interpretado pela bibliografia como reforçador e empático, além de obter julgamentos de maior persuasividade, credibilidade e, no caso específico de terapeutas, tanto o olhar como o sorrir aliam-se a avaliações de maior cordialidade e competência. Também pode indicar dominância (ARGYLE, 1988) Os terapeutas apresentaram um alto índice de olhar, conforme pode ser visualizado na figura 3 .

\section{FIGURA 3 - FREQÜÊNCIA DE DIREÇÃO DE OLHAR VOLTADA PARA O PACIENTE, APRESENTADA POR CADA TERAPEUTA, NAS TRÊS SESSÕES ANALISADAS}

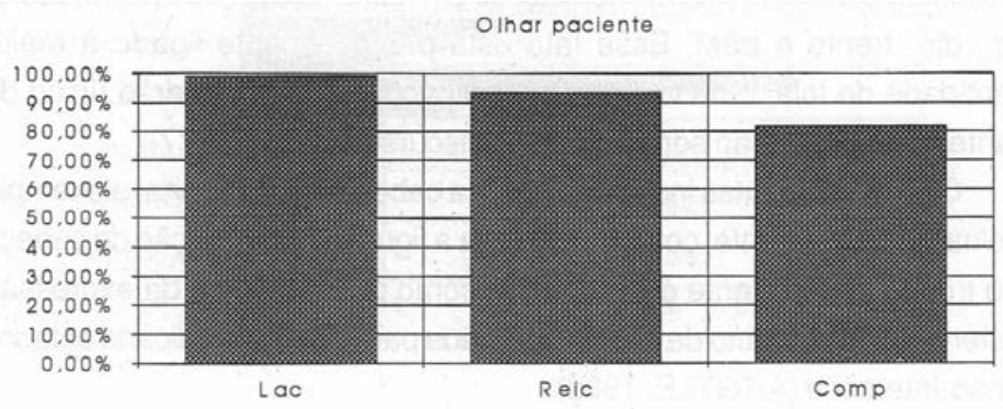


Os desvios de olhar são relatados como padrões típicos do falante na interação, o que quer dizer que os ouvintes desviam menos seus olhares dos interlocutores do que o contrário. $O$ desvio de olhar pode ser considerado também como uma forma de time out ou retirada de atenção. O padrão de desvio de olhar é crescente para os terapeutas em questão, considerando a abordagem teórica na seguinte ordem: lacaniana (menos desvios), reichiano (posição intermediária) e comportamental (maior número de desvios). Estes dados encontram-se representados na figura 4.

\section{FIGURA 4 - FREQÜÊNCIA TOTAL DE DESVIOS DE OLHAR NAS DIREÇÕES BAIXO, CIMA, ESQUERDA E DIREITA, APRESENTADA PELOS TRÊS TERAPEUTAS}

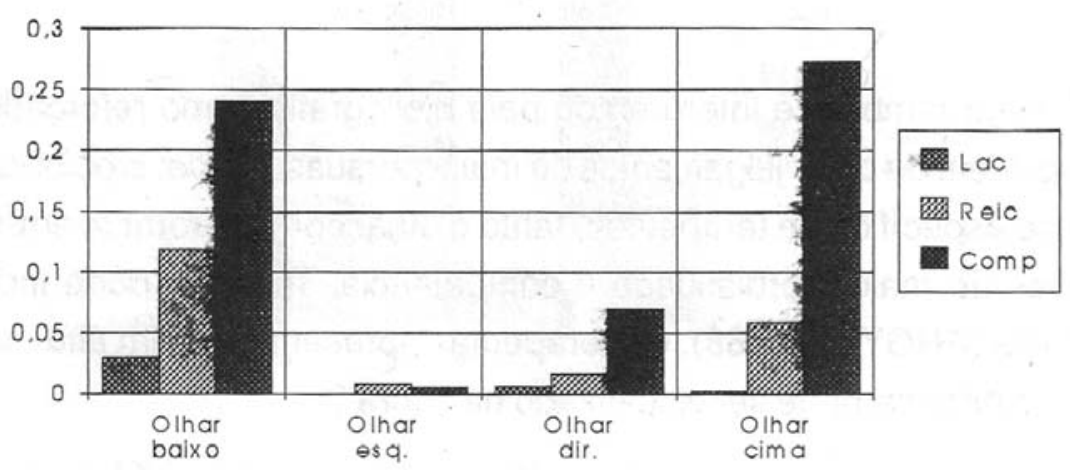

Em relação à inclinação de cabeça, a terapeuta comportamental apresentou a maior média de inclinações em todas as direções (cima, baixo, esq., dir., frente e trás). Esse fato está provavelmente ligado à maior quantidade de fala, uma vez que as inclinações são um padrão típico do falante que se move ao som do próprio discurso (DAVIS, 1977).

Os três terapeutas inclinaram mais a cabeça para a direita (a exemplo do olhar) e para a frente, conforme mostra a figura 5. A inclinação de cabeça e de tronco para a frente é encontrada 